\title{
Effects of A-elements $(\mathrm{A}=\mathrm{Si}$, Ge or $\mathrm{Sn})$ on the structure and electrical contact properties of Ti-A-C-Ag nanocomposites
}

\author{
Jonas Lauridsen, Per Eklund, Jens Jensen, A. Furlan, A. Flink, A. M. Andersson, \\ U. Jansson and Lars Hultman
}

\section{Linköping University Post Print}

\begin{abstract}
N.B.: When citing this work, cite the original article.
\end{abstract}
Original Publication:

Jonas Lauridsen, Per Eklund, Jens Jensen, A. Furlan, A. Flink, A. M. Andersson, U. Jansson and Lars Hultman, Effects of A-elements $(\mathrm{A}=\mathrm{Si}, \mathrm{Ge}$ or $\mathrm{Sn})$ on the structure and electrical contact properties of Ti-A-C-Ag nanocomposites, 2012, Thin Solid Films, (520), 16, 51285136.

http://dx.doi.org/10.1016/j.tsf.2012.04.037

Copyright: Elsevier

http://www.elsevier.com/

Postprint available at: Linköping University Electronic Press

http://urn.kb.se/resolve?urn=urn:nbn:se:liu:diva-72225 


\title{
Effects of A-elements $(A=S i, G e$ or $S n)$ on the structure and electrical contact properties of Ti-A-C- \\ Ag nanocomposites
}

\author{
J. Lauridsen $^{\mathrm{a}^{*}}$, P. Eklund ${ }^{\mathrm{a}}$, J. Jensen ${ }^{\mathrm{a}}$, A. Furlan ${ }^{\mathrm{b}}$, A. Flink ${ }^{\mathrm{c}}$, A. M. Andersson ${ }^{\text {d }}$, U. \\ Jansson $^{\mathrm{b}}$, and L. Hultman ${ }^{\mathrm{a}}$ \\ ${ }^{a}$ Thin Film Physics Division, Department of Physics, Chemistry, and Biology, IFM, \\ Linköping University, SE-581 83 Linköping, Sweden \\ ${ }^{b}$ Department of Materials Chemistry, The Ångström Laboratory, Uppsala University, \\ P.O. Box 538, SE-75121 Uppsala, Sweden \\ ${ }^{c}$ Impact Coatings AB, Westmansgatan 29, SE-582 16 Linköping, Sweden \\ ${ }^{d}$ ABB Corporate Research, Forskargränd 7, SE-721 78, Västerås, Sweden
}

\begin{abstract}
Ti-A-C-Ag (A is $\mathrm{Si}, \mathrm{Ge}$ or $\mathrm{Sn}$ ) nanocomposite coatings have been deposited by dc magnetron sputtering in an ultra high vacuum chamber. Electron microscopy, energydispersive x-ray spectroscopy, x-ray photoelectron spectroscopy, and x-ray diffraction show that all coatings contain nanocrystalline $\mathrm{TiC}$ and $\mathrm{Ag}$ grains in a matrix of mainly amorphous $\mathrm{C}$. A C/Ti ratio above unity yields a homogenous distribution of $\mathrm{Ag}$ with a reduced grain size. From a chemical point of view, the addition of $\mathrm{Ge}$ and $\mathrm{Sn}$ to the Ti-C-
\end{abstract}

\footnotetext{
* Corresponding author. E-mail address: jonla@ifm.liu.se (J. Lauridsen).

Linköping University, IFM, SE-581 83 Linköping, Sweden. Tel.: +46 13282976; Fax: +46 13137568.
} 
Ag system should increase the conductivity of the coatings since the formation of more metallic phases than Si. We demonstrate that Si can be replaced with Ge and $\mathrm{Sn}$ and still yield a homogeneous distribution of Ag. The incorporation of $\mathrm{Ge}$ and $\mathrm{Sn}$ to the Ti-C-Ag system results in elemental precipitation and intermetallic phases, respectively. This gives improved electrical properties compared to Ti-Si-C-Ag coatings, and a contact resistance at loads of $\sim 1 \mathrm{~N}$ against an $\mathrm{Au}$ probe (radius of $0.7 \mathrm{~mm}$ ) that is comparable to that of $\mathrm{Ag}$.

Keywords: Multifunctional coatings; Nanocrystalline; Electron microscopy; Contact resistance; $\mathrm{TiC} ; \mathrm{Ag}$.

\section{Introduction}

Noble metals are commonly employed in electrical contact applications, since they are good conductors and chemically stable. However, in many situations their wear rate is high [1], which limits the life time of an electrical contact. This in combination with high raw material prices motivates investigations for alternative solutions. While others have studied TiC-based nanocomposites as tribological coatings [2,3,4,5,6,7,8,9], we found that such nanocomposites can function as an electrical contact material $[10,11,12,13,14,15,16,17,18,19]$. In our previous works, coatings consisting of nanocrystalline (nc) $\mathrm{TiC}$ embedded in an amorphous (a) $\mathrm{C}$ or $\mathrm{SiC}$ matrix were deposited by dc magnetron sputtering. Magnetron sputtering is a more environmentally friendly deposition technique compared to electroplating, which is the most frequently used technique today for electrical contacts. TiC-based nanocomposite coatings combine good electrical properties with high wear-resistance and a low friction coefficient $[10,13,14,20]$. In order to lower the contact resistance further and allow for applications at low currents 
and loads, Ag was added to the ternary (Ti-Si-C) system [11,12]. This results in lower contact resistance and resistivity. For economic reasons and to make the range of contact applications wider, it is preferred to keep the Ag content as low as possible, and to have Ag homogenously distributed at the percolation limit. It is also desired to have dense coatings since that improves the resistance to corrosion. Our previous studies showed that from an electrical contact material point of view the presence of Si had a favorable influence since it made it possible to tailor the Ag size and distribution [11]. Furthermore, we showed that a homogenous microstructure in the Ti-Si-C-Ag coatings is achieved for a high $\mathrm{C} / \mathrm{Ti}$ ratio [11]. The amorphous $\mathrm{SiC}$ matrix in the Ti-Si-C-Ag coatings, however, reduces the coating conductivity. It is thus of interest to replace the Si by another element, while maintaining a homogenous distribution of Ag.

The group-14 elements $\mathrm{Si}, \mathrm{Ge}$, and Sn show similarities, but also important differences. For example, the metallicity increases in the series $\mathrm{Si}, \mathrm{Ge}$, and $\mathrm{Sn}$. Also, the tendency to form carbides is strongly reduced for Ge and $\mathrm{Sn}$ compared to $\mathrm{Si}$. The Ge-C system exhibits no stable compounds and has negligible mutual solubility. However, $\mathrm{Ge}_{1-\mathrm{x}} \mathrm{C}_{\mathrm{x}}$ alloys with rather low $\mathrm{x}$-values can form at nonequilibrium conditions in coatings [21]. $\mathrm{Sn}$ is not known to form any carbides. Moreover, the tendency to react with $\mathrm{Ag}$ is also different. Si exhibits a very low solubility in Ag and forms no stable silicides [22]. Ge, on the other hand has a rather high solubility in $\mathrm{Ag}$ (about 10 at.\%) and can form at least one metastable germanide, $\mathrm{Ag}_{3} \mathrm{Ge}$ [23]. In contrast, $\mathrm{Sn}$ is more metallic and forms several thermodynamically stable intermetallic phases such as $\mathrm{Ag}_{3} \mathrm{Sn}$ and $\mathrm{Ag}_{4} \mathrm{Sn}$ [22]. Consequently, it is conceivable that Ti-A-C-Ag coatings with $\mathrm{A}=\mathrm{Ge}$ or $\mathrm{Sn}$ give a phase 
distribution with more conductive phases, which is desired for electrical contact applications.

The aim of this study is to deposit Ti-A-C-Ag nanocomposite coatings with $\mathrm{A}=\mathrm{Si}, \mathrm{Ge}$, and $\mathrm{Sn}$, and evaluate the effect of this variation on phase composition and electrical properties. For comparison, a series of Ti-C-Ag coatings without an A-element is included in the study.

\section{Experimental details}

Ti-A-C-Ag coatings were deposited by dc magnetron sputtering in an ultra high vacuum deposition system (base pressure below $6.5 \times 10^{-6} \mathrm{~Pa}$ ) from one $75 \mathrm{~mm} \mathrm{TiC}$ (42:58 at.\%) composite target and two elemental targets, $50 \mathrm{~mm} \mathrm{Ag}$ and $75 \mathrm{~mm} \mathrm{~A} \mathrm{(Si,} \mathrm{Ge,} \mathrm{or} \mathrm{Sn}$ ) or $\mathrm{Ti}$, in an Ar discharge. The targets were positioned $18 \mathrm{~cm}$ from the substrates, two of them at an angle of $35^{\circ}$, and the $\mathrm{Ag}$ target facing it. Substrates of $\mathrm{Si}$ and $\mathrm{SiO}_{2}$ wafers (both $15 \times 15 \times 0.5 \mathrm{~mm})$, and Ni-plated bronze $(15 \times 15 \times 1 \mathrm{~mm})$ were put on a rotating substrate holder facing the targets. During deposition, a constant-current condition, a constant dc bias of $-50 \mathrm{~V}$, a pressure of $0.53 \mathrm{~Pa}$, and a substrate temperature of $300{ }^{\circ} \mathrm{C}$ were applied. Four different coatings per material system were deposited with the combinations of low and high Ag and A-element/Ti content, see Table 1.

The deposition conditions were chosen on the basis of [11], where the effect of Si and Ag content on the microstructure was studied. Constant-current conditions for the TiC target 
was chosen in order to achieve more or less equal C/Ti ratio for the coatings with same A-element, except for the Ti-C-Ag coatings, where the Ti content is varied, see Table 1. $\mathrm{X}$-ray diffraction $(\mathrm{XRD})$ in gracing incidence (GI) mode with an incidence angle of $2^{\circ}$ was performed on a Philips diffractometer equipped with a $\mathrm{Cu} \mathrm{K} \alpha$ x-ray source operating at $40 \mathrm{kV}$ and $40 \mathrm{~mA}$.

Time-of-flight energy elastic recoil detection analysis (ToF-E ERDA) was performed at the Uppsala Tandem Laboratory to measure the elemental composition of the coatings. We used $40 \mathrm{MeV}^{127} \mathrm{I}^{9+}$ projectile ions at $22.5^{\circ}$ incident angle and a detector placed at a recoil scattering angle of $45^{\circ}$ [24]. The elemental composition of the Ti-Sn-C-Ag coatings was determined with X-ray photoelectron spectroscopy, as the Sn and Ag overlap in the ToF-E ERDA spectra due to the finite mass resolution.

X-ray photoelectron spectroscopy (XPS) measurements were performed on a Physical Electronics Quantum 2000 spectrometer using monochromatic Al Ka radiation. High resolution XPS spectra were recorded after $90 \mathrm{~s}$ of sputter etching with $4 \mathrm{kV} \mathrm{Ar}^{+}$ions, over an area of $2 \times 2 \mathrm{~mm}^{2}$.

Scanning electron microscopy (SEM) was performed using a LEO 1550 microscope. Both cross-sectional and plan-view images were obtained by using accelerating voltages of 5-10 kV and an inlens detector. Thickness measurements of the coatings were performed on the coatings deposited onto Si substrates. 
Transmission electron microscopy (TEM), high-resolution TEM (HRTEM), and scanning TEM (STEM) images were obtained on a Tecnai $\mathrm{G}^{2} 20$ U-Twin $200 \mathrm{kV}$ FEGTEM. Analytical TEM was performed using energy-dispersive x-ray spectroscopy (EDX) in STEM mode at a camera length of $170 \mathrm{~mm}$. Cross-section samples were mechanically polished, and ion milled with $5 \mathrm{keV}$ Ar ions to electron transparency with a final polishing step with $2.5 \mathrm{keV}$ by a Gatan Precision Ion Polishing System (PIPS).

Room-temperature four-point-probe measurements were performed using a Jandel Engineering instrument, with a WC probe. The obtained sheet resistance was then multiplied with the coating thickness to obtain the resistivity.

Contact resistance was measured with a four-wire in-house setup, see Figure 1. An Ohm meter is connected to the central Au probe (diameter $1.4 \mathrm{~mm}$ ) and the sample with a crocodile clamp. The sample table is pressed towards the spring-connected Au probe with a step length that results in a load of a few tens of $\mathrm{mN}$, as measured with a force gauge (Lutron FG-5000A); the sample table is held for $\sim 3$ s to get a stable resistance value. This is done both when the sample is loaded and unloaded. A $1 \mathrm{~mA}$ current is applied and the voltage drop is measured. In this setup, there are contributions from the resistance in the Au probe $\left(R_{i 1}\right.$, as defined in Figure 1$)$, and a leakage current $i_{R}$. The contribution from $i_{R}$ is negligibly small. Since $\mathrm{R}_{\mathrm{i} 1}$ is constant, and very low, in practice only the contact resistance $R_{c 1}$ is measured. The contact resistance depends on which substrate the coatings are deposited on. Therefore, a dc magnetron sputtered Ag reference is added to each electrical contact graph for comparison, and all coatings are deposited on Ni-plated bronze. 


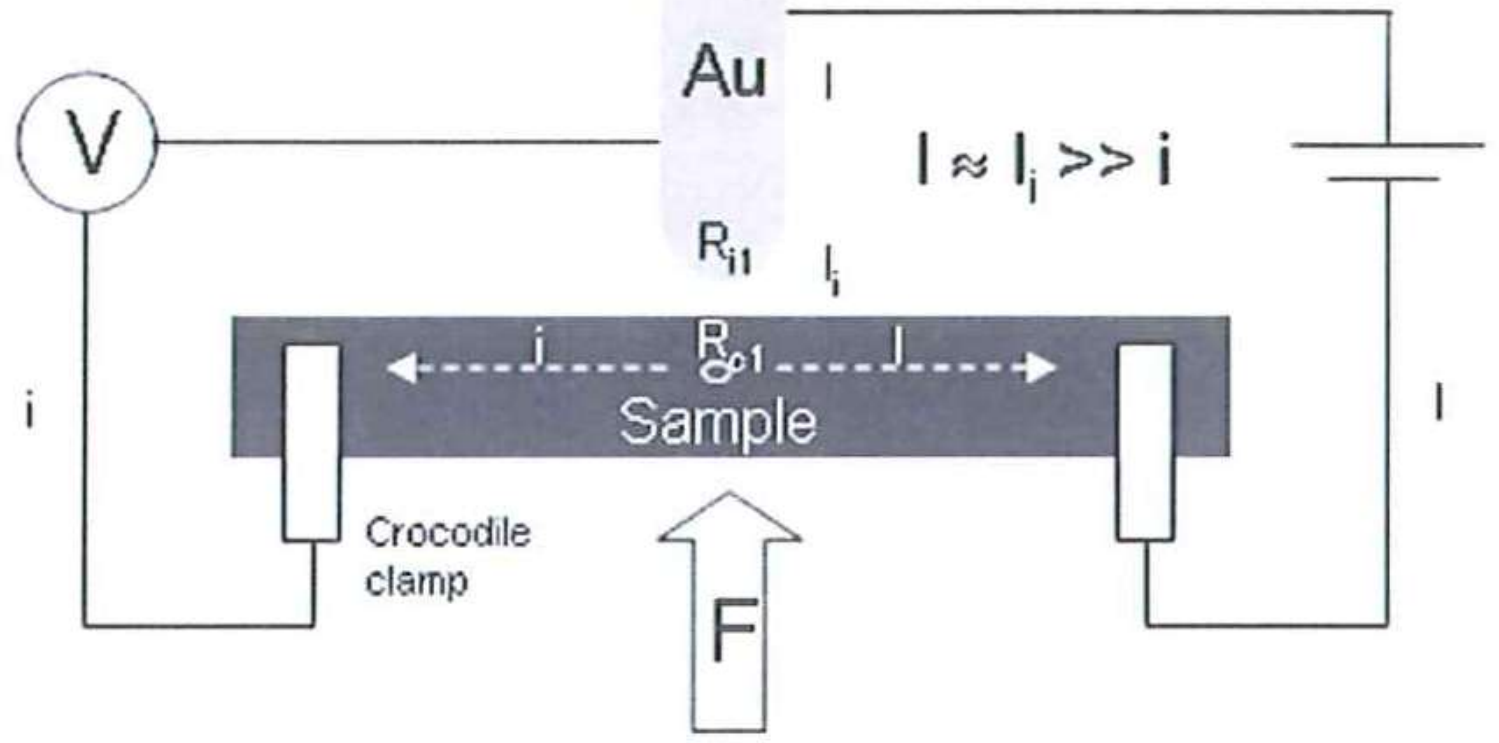

Figure 1. Schematic image of the electrical contact measurement setup.

\section{Results}

Table 1 shows the composition of Coatings 1-16. Within each materials system, both the $\mathrm{Ag}$ and A-element/Ti contents were varied in two levels resulting in four different compositions. All coatings have a $\mathrm{N}$ content in the range 1.8-6.4 at.\%. Coatings 1, 2, and 5-8 have a $\mathrm{O}$ content $<1$ at. $\%$, while Coatings 3,4 , and 9-16 have a $\mathrm{O}$ content in the range 2.1-8.4 at.\%. The coatings have a $\mathrm{C} / \mathrm{Ti}$ ratio $>1$, meaning that there is no free $\mathrm{Ti}$ in the coatings. All $\mathrm{Ti}$ bonds to $\mathrm{C}$; when the maximum fraction of $\mathrm{C}$ in $\mathrm{TiC}_{\mathrm{x}}(\mathrm{x} \approx 0.47-0.97)$ $[25,26]$ is exceeded, the excess $\mathrm{C}$ bonds to $\mathrm{Si}, \mathrm{Ge}$, or $\mathrm{C}$.

Figure 2a shows the $\mathrm{x}$-ray diffractograms from Coatings 1-4 (no A-element present). TiC and $\mathrm{Ag}$ are the only crystalline phases in these coatings. The $\mathrm{TiC}$ and $\mathrm{Ag}$ peak intensities 
increase with increased $\mathrm{Ti}$ and $\mathrm{Ag}$ content, respectively. The TiC 111 peak has a shift to lower $2 \theta$ values. The Ag and TiC grain sizes were estimated by Scherrer's formula to be 5-9 $\mathrm{nm}$ and 5-15 nm, respectively. The Ag peak from Coating 1 overlaps with TiC 111, which makes it difficult to estimate the Ag grain size in that coating.

Figure $2 \mathrm{~b}$ shows $\mathrm{XRD}$ diffractograms of Coatings $5-8(\mathrm{~A}=\mathrm{Si})$. $\mathrm{Ag}$ is the main crystalline phase; however, small and broad $\mathrm{TiC}$ peaks are also present, which indicates that $\mathrm{TiC}$ is nanocrystalline. The Ag grain size was estimated to $15-30 \mathrm{~nm}$ by Scherrer's formula. The intensity of the Ag peaks increases for increased Ag content in the coatings.

Figure 2c shows XRD diffractograms of Coatings 9-12 ( $\mathrm{A}=\mathrm{Ge})$. Ag, TiC, and also $\mathrm{Ge}$ phases are present. The TiC peaks are broad with low intensity, which indicates that $\mathrm{TiC}$ is nanocrystalline. The Ag and Ge peak intensities increase with increased content of those elements. The Ag, Ge, and TiC grain sizes were estimated by Scherrer's formula to 7-11 nm, $10-15 \mathrm{~nm}$, and $\sim 5 \mathrm{~nm}$, respectively.

Figure 2d shows XRD diffractograms of Coatings 13-16 (A=Sn). Ag and Sn forms the intermetallic phase $\mathrm{Ag}_{3} \mathrm{Sn}$. For Coating 14, a peak shift of $\mathrm{Ag}_{3} \mathrm{Sn} 201$ and 211 is observed. The possibility that these peaks could be from overlap with any $\mathrm{Ti}_{3} \mathrm{Sn}$ can be excluded based on the XPS and STEM/EDX results below, which show no evidence of such a phase. Instead the shift of the $\mathrm{Ag}_{3} \mathrm{Sn}$ peaks could be caused by stress in the coating. The $\mathrm{Ag}_{3} \mathrm{Sn}$ peak intensities increase with increased $\mathrm{Ag}$ content. For the coatings with higher Sn content, Sn precipitats. A small TiC 111 peak is noticed. The Ag 111 and 200 peaks are shifted to higher 2 theta angles. The Ag 200 peak overlaps with Sn 220 and Sn 211, and is therefore not visible in Figure 2d for Coatings 15 and 16. The $\mathrm{Ag}_{3} \mathrm{Sn}$ and $\mathrm{Sn}$ grain sizes were estimated to $15-21 \mathrm{~nm}$ and $17-25 \mathrm{~nm}$, respectively. 


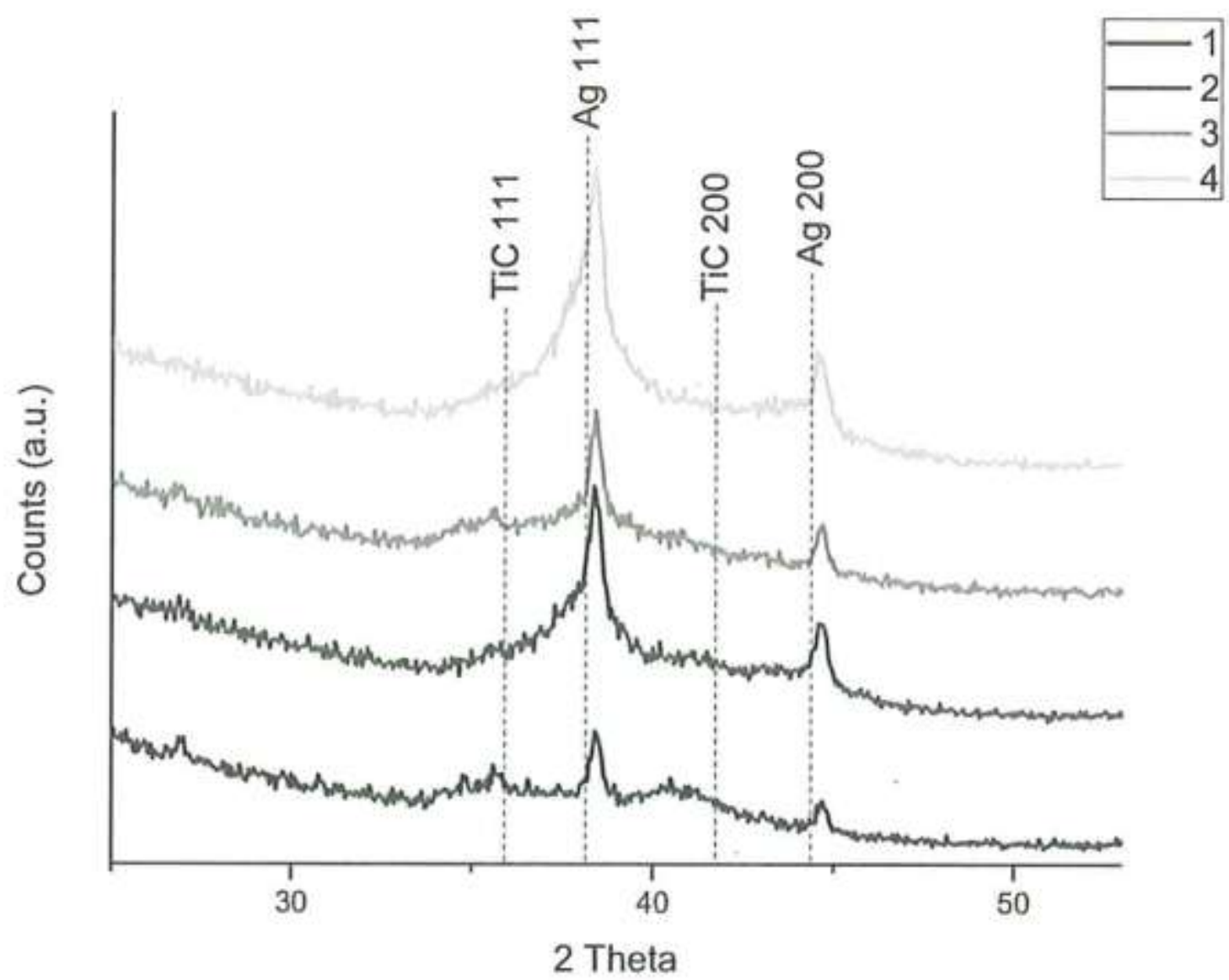

Figure 2. X-ray diffractograms in gracing incident geometry from Coatings 1-16.

Figure 3a shows XPS spectra in the C1s region from Coatings 4, 8, 12, and 16 . Three major peaks in these coatings are exhibit at $281.7 \mathrm{eV}, 282.4 \mathrm{eV}$, and $284.3 \mathrm{eV}$, which correspond to $\mathrm{C}-\mathrm{Ti}, \mathrm{TiC}^{*}$, and $\mathrm{C}-\mathrm{C}$, respectively. $\mathrm{TiC}^{*}$ has been found previously in $\mathrm{TiC}$ nanocomposite coatings, as discussed in $[27,28,29]$. For the Si and Ge-containing coatings, C-Si and C-Ge bonds are observed at $282.4 \mathrm{eV}$ and $283.4 \mathrm{eV}$, respectively. XPS reveals that the peaks in the Ti2p region are observed at $454.7 \mathrm{eV}\left(\mathrm{Ti} 2 \mathrm{p}_{3 / 2}\right)$ and $460.7 \mathrm{eV}$ (Ti2 $\mathrm{p}_{1 / 2}$ ) for all coatings (not shown). This is as a result of the Ti-C bonding. 

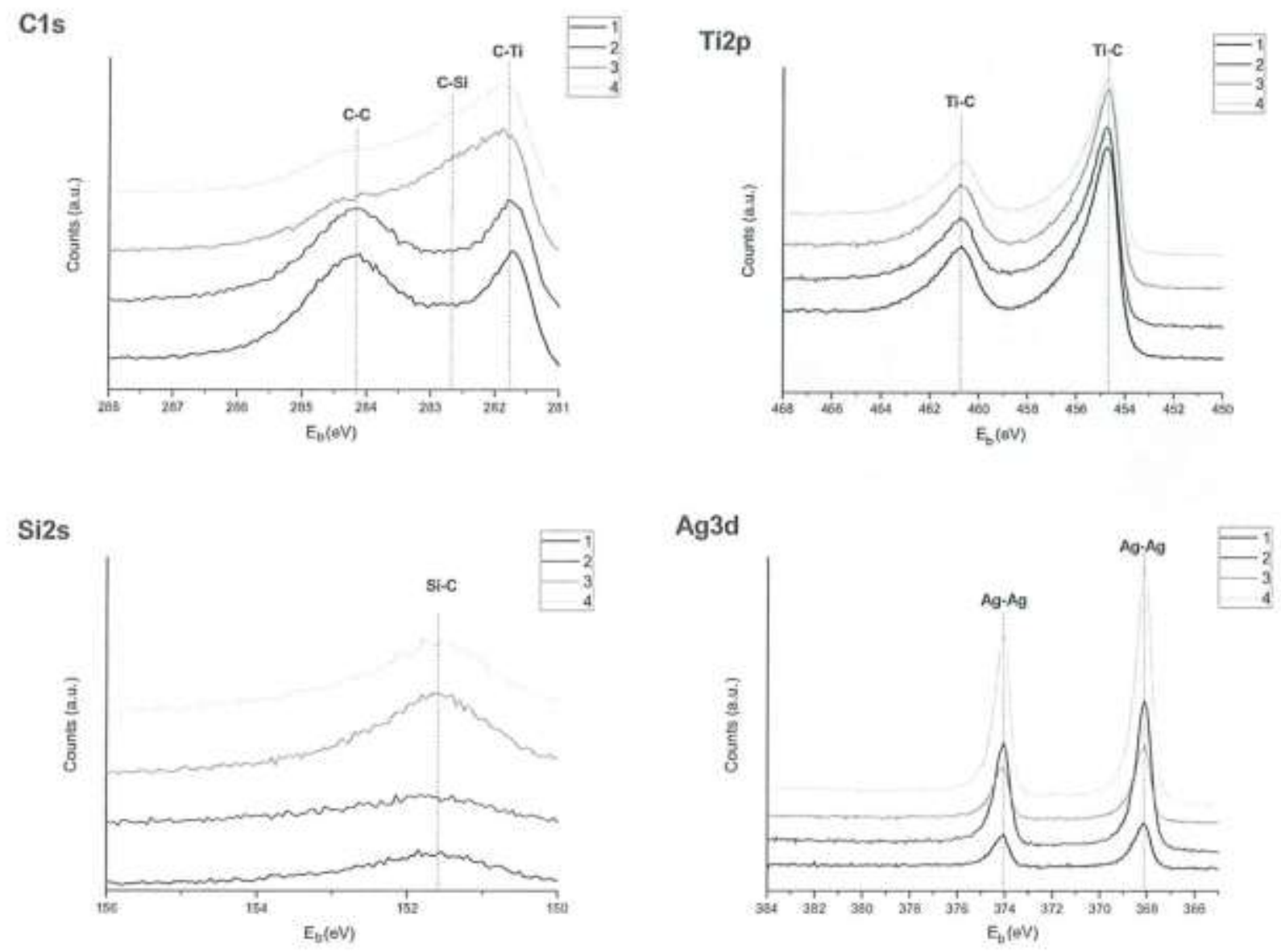

Figure 3. XPS spectra from different regions, a) The C1s region from Coatings 4, 8, 12, and 16, b) Si2s region from Coatings 5-8, c) Ge2p region from Coatings 9-12, and d) Ag3d region from Coatings 13-16.

For Coatings 1-4, peaks in the $\mathrm{Ag} 3 \mathrm{~d}$ region were observed at $374.2 \mathrm{eV}\left(\mathrm{Ag} 3 \mathrm{~d}_{3 / 2}\right)$ and $368.1 \mathrm{eV}\left(\mathrm{Ag}_{3} \mathrm{~d}_{5 / 2}\right)$ (not shown), which correspond to Ag-Ag bonds. The position and shape of the Ag3d peaks are similar in all Ti-C-Ag coatings, while Coatings 1 and 2 contain more free $\mathrm{C}$ and less $\mathrm{C}$-Ti bonds in the $\mathrm{C} 1 \mathrm{~s}$ region than Coatings 3 and 4 (not shown).

Figure $3 \mathrm{~b}$ shows the Si2s region for Coatings 5-8. Note that the Si2s region was studied instead of the commonly considered Si2p region since the Si2p region overlaps with the 
broad $\mathrm{Ag} 4 \mathrm{~s}$ region. The peak in the $\mathrm{Si} 2 \mathrm{~s}$ region is located at $151.6 \mathrm{eV}$, which corresponds to $\mathrm{Si}-\mathrm{C}$ bonds. The intensity of the Si2s peak increased with increased $\mathrm{Si}$ content. The peaks in the $\mathrm{C} 1 \mathrm{~s}$ region observed at $281.7 \mathrm{eV}, 282.4 \mathrm{eV}$, and $284.3 \mathrm{eV}$ are attributed to $\mathrm{C}-\mathrm{Ti}, \mathrm{C}-\mathrm{Si}$, and $\mathrm{C}-\mathrm{C}$ bonds, respectively. With increased $\mathrm{Si}$ content in the coatings, the C-Si peak intensity increases while the C-C peak decreases. No effect on the TiC bonds is found when the Si or Ag contents are changed. Peaks in the Ag3d region are observed at $374.2 \mathrm{eV}\left(\mathrm{Ag} 3 \mathrm{~d}_{3 / 2}\right)$, and $368.1 \mathrm{eV}\left(\mathrm{Ag} 3 \mathrm{~d}_{5 / 2}\right)$, which are equivalent to $\mathrm{Ag}-\mathrm{Ag}$ bonds for which the difference in intensity is related to the difference in Ag content (not shown).

Figure $3 c$ shows the Ge2p region for Coatings 9-12. A peak at $1217.4 \mathrm{eV}$ is observed, equivalent to free Ge. An increased Ge content yields an increased amount of free Ge. From the $\mathrm{C} 1 \mathrm{~s}$ region three peaks are found at $281.7 \mathrm{eV}, 283.4 \mathrm{eV}$, and $284.3 \mathrm{eV}$, which correspond to $\mathrm{C}-\mathrm{Ti}, \mathrm{C}-\mathrm{Ge}$, and $\mathrm{C}-\mathrm{C}$ bonds, respectively (Figure 3a, Coating 12). The peaks in the $\mathrm{C} 1 \mathrm{~s}$ region have the same binding energy and similar intensities for all TiGe-C-Ag coatings (not shown). Peaks in the Ag3d region at $374.2 \mathrm{eV}\left(\mathrm{Ag}_{3} \mathrm{~d}_{3 / 2}\right)$, and $368.1 \mathrm{eV}\left(\mathrm{Ag} 3 \mathrm{~d}_{5 / 2}\right)$ correspond to Ag-Ag bonds (not shown).

Figure $3 \mathrm{~d}$ shows the $\mathrm{Ag} 3 \mathrm{~d}$ region for Coatings $13-16$, where shifts from $368.1 \mathrm{eV}$ to $368.3 \mathrm{eV}$ and $374.2 \mathrm{eV}$ to $374.3 \mathrm{eV}$ are observed. The peaks in the Sn3d region are observed at $484.8 \mathrm{eV}, 486.3, \mathrm{eV}, 493.2 \mathrm{eV}$, and $494.9 \mathrm{eV}$, which corresponds to $\mathrm{Sn}-\mathrm{Sn}$ and Sn-O bonds (not shown) [30]. Both the Sn-Sn and Sn-O intensity increases with increased Sn content. Coating 15 and 16 have an additional peak in the Ti2p region at $458.5 \mathrm{eV}$, which is equivalent to Ti-O bonds. The peaks in the $\mathrm{C} 1 \mathrm{~s}$ region are located at $281.7 \mathrm{eV}$ and $284.3 \mathrm{eV}$, which stems from C-Ti and C-C bonds (Figure 3a, Coating 16). These peaks have the same binding energy with similar intensity for all Ti-Sn-C-Ag coatings (not shown). 
Figure 4 shows plan-view and cross-sectional SEM images of one coating from each investigated material system; specifically Coatings $2,6,10$, and 14, which have low Aelement content and high $\mathrm{Ag}$ content. Figure $4 \mathrm{a}$ shows that Coating 2 is dense and has relatively large particles located at the surface. The bright spherical features on the surface are Ag particles as identified by EDX and Helium ion microscopy in similar coatings in a previous study [11]. Figure $4 \mathrm{~b}$ shows that Coating 6 is dense and has a smooth surface with small Ag particles. Figure 4c shows that Coating 10 is dense and has a rougher surface morphology than both Coatings 2 and 6. The size of the Ag particles is similar to Coating 6 . Figure $4 \mathrm{~d}$ shows that Coating 14 is porous with a rough nodular surface morphology, with Ag particle size similar to Coating 2. The surface roughness differs between the four material systems; but the fact is that the surface roughness increases with increased $\mathrm{Ag}$ and A-element content in all four material systems. 


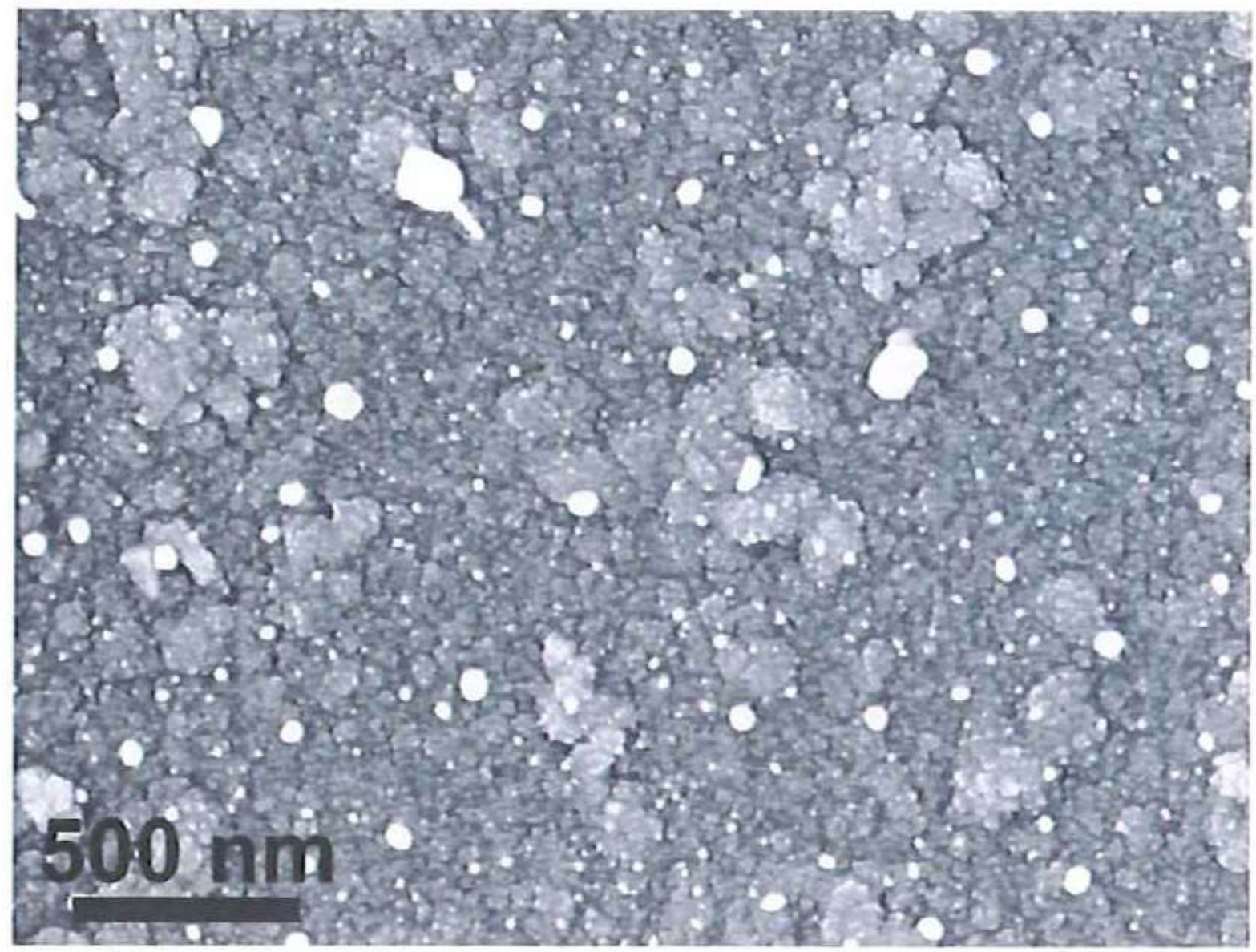

Figure 4. Plan-view and cross sectional SEM images of a) Coating 2, b) Coating 6, c) Coating 10, and d) Coating 14.

Figure 5a shows overview TEM, with corresponding selected area electron diffraction (SAED) pattern, and HRTEM images from Coating 2. The size of the Ag precipitates varies, but the distribution is relatively homogenous. The SAED pattern shows that TiC and Ag are the only crystalline phases. A typical multiple twinned Ag grain with the size of $\sim 5 \mathrm{~nm}$ is shown in the HRTEM image. Figure $5 \mathrm{~b}$ shows corresponding electron microscopy images from Coating 6. There is a relatively homogenous distribution of $\mathrm{Ag}$ precipitates. A closer inspection (not shown here) revealed grains of the size 1-2 nm with d-spacing corresponding to TiC. The HRTEM inset shows a $\sim 4 \mathrm{~nm}$ multiple twinned $\mathrm{Ag}$ grain from an area close to the coating surface. The SAED inset shows rings from Ag and 
blurry rings where the TiC phase is expected, which confirms the observations from TEM and XRD that the TiC grains are nanocrystalline. For Coating 10, Figure 5c shows that the size of the Ag grains varies around $4 \mathrm{~nm}$. A closer inspection showed that the $\mathrm{TiC}$ grains are $\sim 2 \mathrm{~nm}$. From the SAED pattern it is found that $\mathrm{TiC}, \mathrm{Ag}$, and $\mathrm{Ge}$ are the crystalline phases. Consistently, the $\mathrm{TiC}$ grains are nanocrystalline. Figure $5 \mathrm{~d}$ shows that Coating 14 has $\mathrm{Ag}$ grains with size around $4 \mathrm{~nm}$. The Ag precipitates were homogenously distributed. In the SAED pattern blurry rings are present, which would correspond to nanocrystalline TiC with a grain size too small to be resolved in XRD (c.f. Figure 2d). 


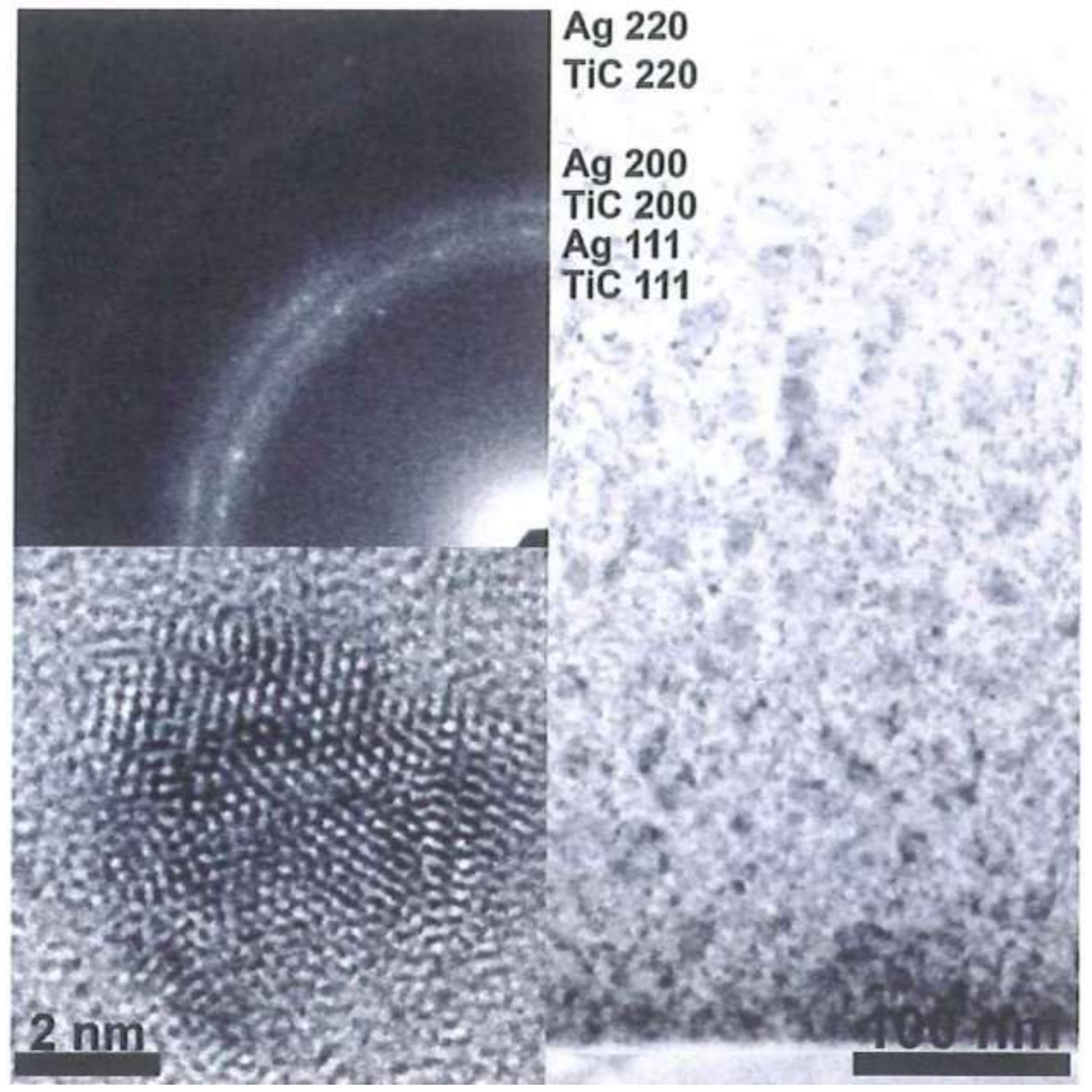

Figure 5. Overview, high resolution TEM, and SAED images of a) Coating 2, b)

Coating 6, c) Coating 10, and d) Coating 14.

Figure 6a shows a STEM image and EDX elemental maps of Coating 2. The bright contrast in the STEM image stems from Ag. There is a distribution of Ag precipitates with a size around $\sim 10 \mathrm{~nm}$ and smaller TiC grains. Figure $6 \mathrm{~b}$ shows the corresponding 
analysis of Coatings 6. The EDX map area displays both large and small Ag precipitates, where the larger $\mathrm{Ag}$ precipitates have a size of $\sim 20 \mathrm{~nm}$. The Si signal intensity is higher at the $\mathrm{Ag}$ precipitates, while $\mathrm{Ti}$ is more finely dispersed and with higher signal intensity in between the Ag precipitates. Figure 6c shows a STEM image and EDX elemental maps of Coating 10. In the STEM image homogenously distributed Ag precipitates with a size of $\sim 10 \mathrm{~nm}$ are observed. Ti is mainly located in between Ag, while Ge preferentially overlaps with Ag, but is also recognized as elemental precipitates. For Coating 14 (Figure 6d) the Sn and Ag signals overlap, and are surrounded by Ti. This is consistent with the results from XRD and SAED, and shows the formation of $\mathrm{Ag}_{3} \mathrm{Sn}$. 


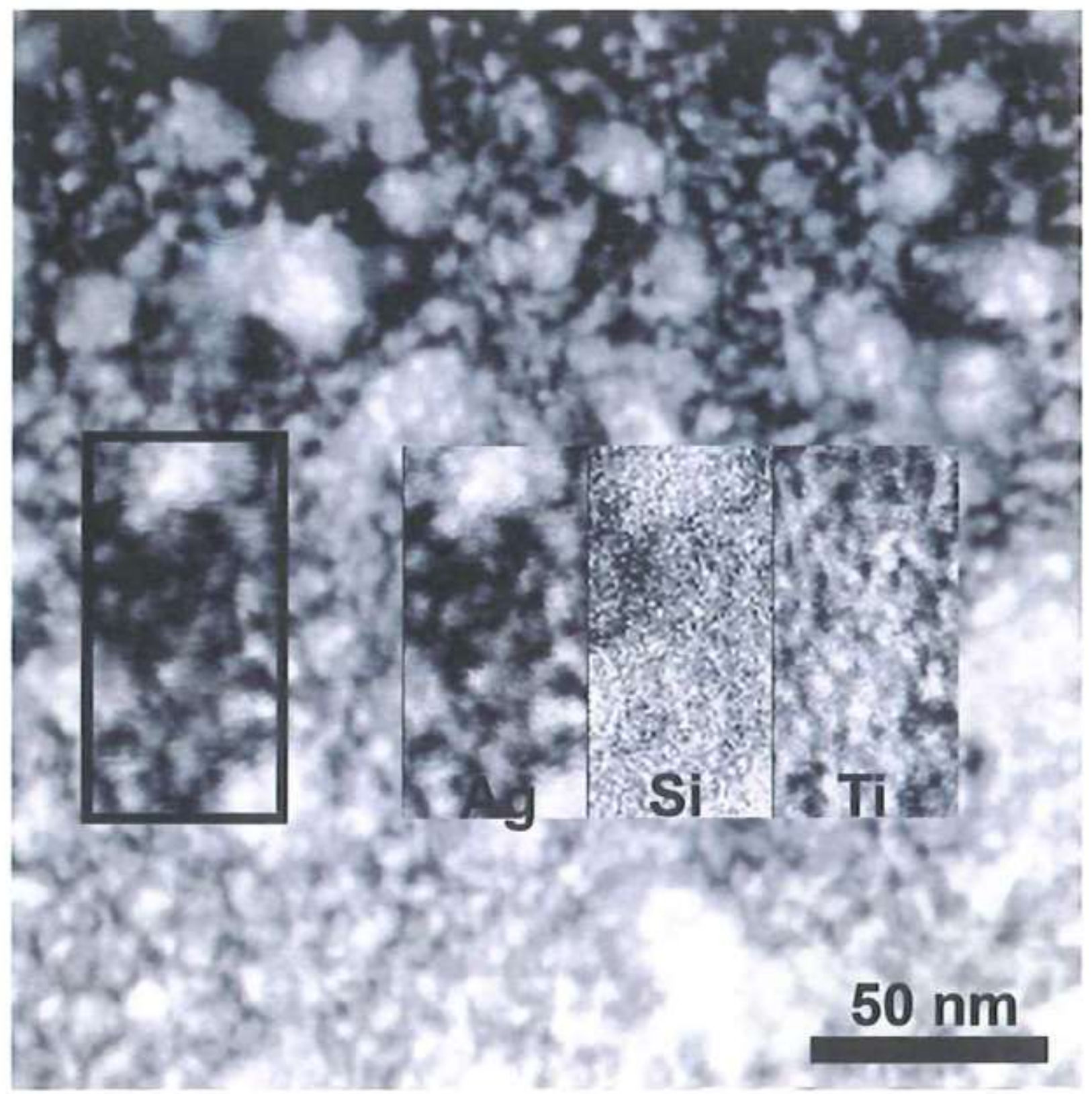

Figure 6. STEM image with a corresponding selected area EDX map from a)

Coating 2 (the black area in the map is damage from the sample preparation), b)

Coating 6, c) Coating 10, and d) Coating 14.

Figure 7 shows contact resistance against an Au probe as a function of contact load for all coatings, including the Ag reference. For Coatings 1-4 (Ti-C-Ag), Figure 7a shows that 
Coating 2 with high $\mathrm{Ag}$ and low $\mathrm{Ti}$ content exhibits the lowest contact resistance of Coatings 1 -4. Coating 1 has a contact resistance above $0.05 \Omega$. Figure $7 \mathrm{~b}$ shows only the contact resistance for Coatings 6 and 8 (Ti-Si-C-Ag) since Coatings 5 and 7 both have a contact resistance above $0.05 \Omega$. Coating 8 , which shows the lowest contact resistance of Coatings 5-8, has roughly 10 times higher contact resistance than the Ag reference. For Coatings 9-12 (Ti-Ge-C-Ag), Figure 7c shows that Coating 9 has the highest contact resistance, while Coatings 10-12 have contact resistance close to the Ag-reference at loads higher than 0.6 N. For Coatings 13-16 (Ti-Sn-C-Ag), Figure 7d shows that Coating 13 has higher contact resistance compared to the three others. It is also observed that an increased Sn content results in an increased contact resistance. In summary, both Ti-C-Ag and Ti-Ge-C-Ag coatings have contact resistances comparable to the Ag reference at loads of $\sim 1 \mathrm{~N}$. 


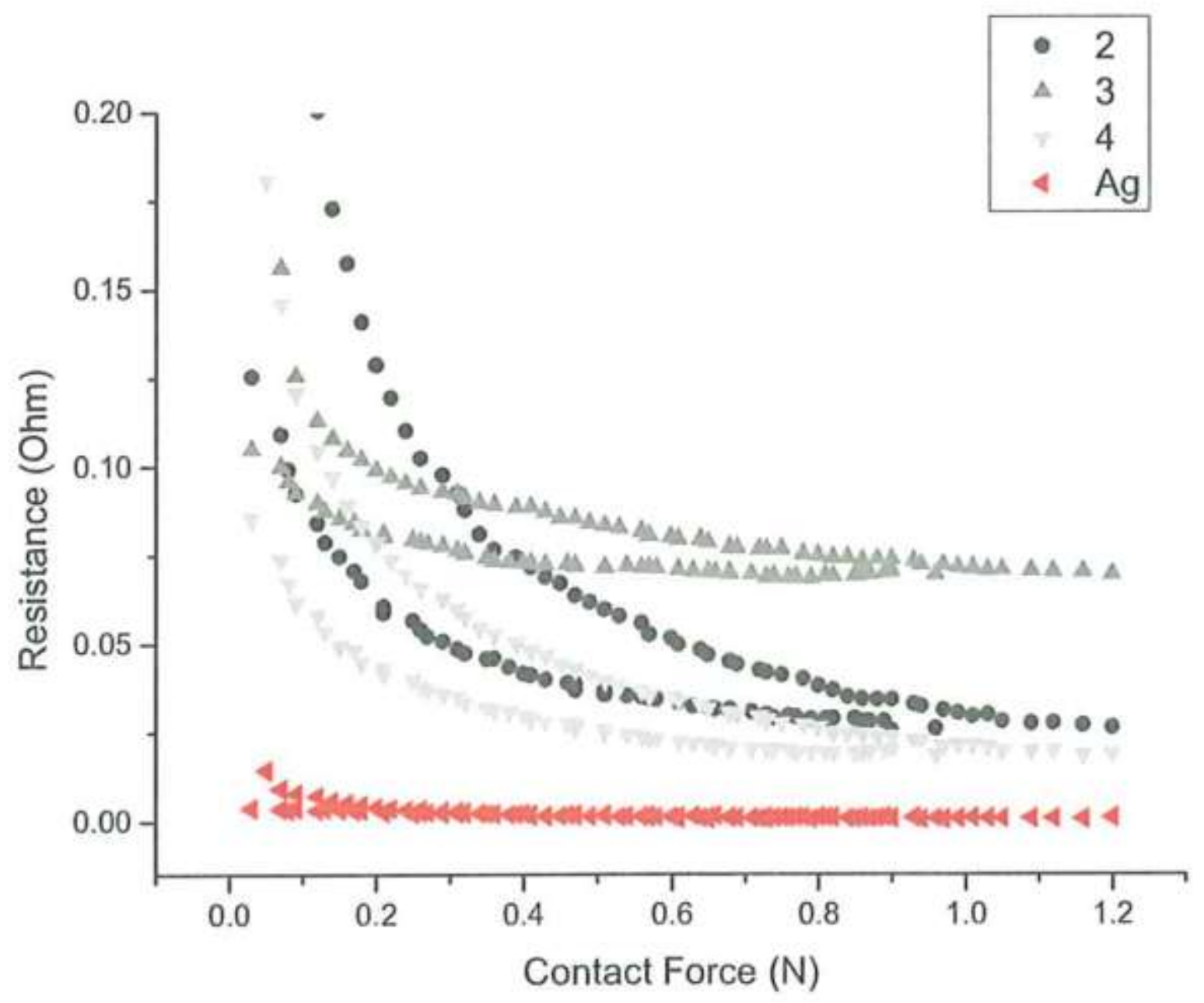

Figure 7. Contact resistances measured under load and unload of Coatings 1-16 and a Ag reference.

Table 1 shows the resistivity of Coatings 1-16. The resistivity of Coatings 1-4 is in the range 200-401 $\mu \Omega \mathrm{cm}$, where the coatings with higher Ag content (Coatings 2 and 4) have the lowest resistivity and Coating 3 with low Ag content and high Ti content has the highest resistivity. The resistivity of Coatings $5-16$ is in the range $274-1094 \mu \Omega \mathrm{cm}$. For Coatings 5-16 an increased $\mathrm{Si}$, Ge or Sn content results in an increased resistivity. 


\section{Discussion}

The Ti-A-C-Ag coatings $(\mathrm{A}=\mathrm{Si}$, Ge or $\mathrm{Sn})$ comprised nanocrystalline $\mathrm{TiC}$ and $\mathrm{Ag}$ in an amorphous matrix. The presence of $\mathrm{TiC}$ in the Ti-C-Ag coatings is apparent from XRD and the $\mathrm{TiC}$ peak shift in these coatings (see Figure 2a) is explained by non-stoichiometry of the $\mathrm{TiC}$ as the lattice parameter varies with $\mathrm{C}$ content [26]. However, addition of an A-element lowered the TiC peak intensity and broadened the peak width in XRD and SAED. Thus, the addition of the A-elements disturbs the TiC grain growth such that the crystallinity and grain size decreases.

In the Ti-C-Ag coatings, $\mathrm{C}$ is mainly bonded to $\mathrm{Ti}$, but there is also a small fraction of free $\mathrm{C}$. For the A-elements, the carbide formation tendency is decreased in the following order $\mathrm{Si}, \mathrm{Ge}$, and $\mathrm{Sn} . \mathrm{Si}$ is a strong carbide former, therefore, $\mathrm{C}$ bonds mainly to $\mathrm{Si}$ and $\mathrm{Ti}$ in the Ti-Si-C-Ag coatings. Ge has less tendency to form carbides than $\mathrm{Si}$, thus less $\mathrm{C}$ is bonded to Ge in the Ti-Ge-C-Ag coatings than to $\mathrm{Si}$ in the Ti-Si-C-Ag coatings. Instead, the $\mathrm{C}$ is mainly bonded to $\mathrm{Ti}$, which is why the amount of free $\mathrm{C}$ increased compared to both the Ti-C-Ag and Ti-Si-C-Ag coatings. Sn does not form any carbides, explaining why the amount of free $\mathrm{C}$ is highest in the Ti-Sn-C-Ag coatings. It is therefore likely that for the $\mathrm{Sn}$ and Ge containing coatings, the amount of the amorphous matrix is primarily dependent on the amount of free $\mathrm{C}$. The amorphous matrix has influences the electrical properties, which will be discussed below.

The small amount of free $\mathrm{C}$ results in an amorphous matrix in the Ti-C-Ag coatings. The formation of such a thin matrix with larger TiC grains than in the coatings with an Aelement leads to less grain boundary scattering, which in turn results in the lowest 
resistivity (200-401 $\mu \Omega \mathrm{cm}$ ). These dense coatings also have a contact resistance comparable with $\mathrm{Ag}$ at loads of $\sim 1 \mathrm{~N}$ against $\mathrm{Au}$, which is explained by the relatively large Ag particles on the surface.

The amount of matrix increased when $\mathrm{Si}$ was added to the Ti-C-Ag coatings. In [11] TiSi-C-Ag coatings were deposited at ambient temperature in a commercial deposition system with deposition rates of $\sim 5 \mu \mathrm{m} / \mathrm{h}$. Although the present elevated substrate temperature $\left(300{ }^{\circ} \mathrm{C}\right)$ and low deposition rate $(\sim 0.2 \mu \mathrm{m} / \mathrm{h})$ should promote grain growth. The TiC grain size in Coatings 5-8 was smaller compared to that in [11]. This indicates that the $\mathrm{SiC}$ matrix can hinder the $\mathrm{TiC}$ grain growth, since the amount of amorphous matrix was higher here than in [11]. Despite the fact that the Ti-Si-C-Ag coatings are dense and with an $\mathrm{O}$ content below 1 at.\%, the resistivity is higher compared to the Ti-CAg coatings since the amorphous matrix consists of $\mathrm{SiC}$ which is less conductive than free C. The amount of matrix is also higher, which further reduces the conductivity. Moreover, Coatings 5-8 have a smooth surface with relatively small Ag particles, which results in an increased contact resistance compared to the Ti-C-Ag coatings, since the electrical contact area decreases with a smother surface morphology and lower amount of high conducting Ag particles. A rough surface morphology decreases the contact resistance since the native surface oxides are more easily penetrated, which in turn increases the electrical contact area [31].

Incorporating $\mathrm{Ge}$ instead of $\mathrm{Si}$ results in more free $\mathrm{C}$. This is because that the carbide forming tendency is lower for $\mathrm{Ge}$ than for $\mathrm{Si}$. In this case, the amount of amorphous matrix is probably similar or slightly lower than the amount of matrix in the Ti-Si-C-Ag 
coatings since the amount of free $\mathrm{C}$ and $\mathrm{SiC}$ is equal or higher than the amount of free $\mathrm{C}$ and $\mathrm{GeC}$. The resistivity for the Ti-Ge-C-Ag coatings is comparable to Ti-Si-C-Ag coatings, but the contact resistance is lower since the surface morphology is rougher and easier penetrates the surface oxide. Furthermore, in the Ti-Si-C-Ag coatings the surface oxide is probably mainly $\mathrm{SiO}_{\mathrm{x}}$ as in Ti-Si-C [32], which is an oxide harder to penetrate than the $\mathrm{TiO}_{\mathrm{x}}$ and $\mathrm{GeO}_{\mathrm{x}}$ that are probably formed in the Ti-Ge-C-Ag coatings.

The largest amount of free $\mathrm{C}$ is obtained in the Ti-Sn-C-Ag coatings, which results in the largest amount of amorphous matrix, this and the porosity of these coatings yields the high resistivity. The porosity together with the rough surface morphology of the Ti-Sn-CAg coatings also results in a contact resistance that is lower than for the dense Ti-Si-CAg coatings with a smooth surface. However, the contact resistance for the Ti-Sn-C-Ag coatings is higher than for the Ti-C-Ag and Ti-Ge-C-Ag coatings, which both have rough surfaces. In addition, the coatings contain 4-8 at.\% O, which also affects the electrical properties.

The Ti-Si-C-Ag, Ti-C-Ag, and Ti-Ge-C-Ag coatings exhibit segregation of $\mathrm{TiC}$ in between the Ag grains. Moreover, since Ag has a drag effect on the A-elements, the Aelements are distributed with a higher concentration at the Ag precipitates. This drag effect can be explained by the eutectic reaction in the Ag-Si and Ag-Ge phase diagrams. As Ag-Si compounds segregates on the growth surface, Ag precipitates while Si reacts with $\mathrm{C}$ to form $\mathrm{SiC}$. The diffusion of $\mathrm{Ag}$ through $\mathrm{Si}$ is fast [33], but when $\mathrm{Si}$ forms $\mathrm{SiC}$ the diffusion becomes limited which quenches the Ag growth. Instead, new Ag grains nucleate continuously on the surface during deposition. This effect can be explained 
similarly for Ag-Ge. The Ag precipitates in the Ti-C-Ag and Ti-Ge-C-Ag coatings are of varying size, but homogenously distributed. Hence, the quenching of the Ag grain growth in these coatings is not as efficient as in the Ti-Si-C-Ag coatings.

For the Ti-Si-C-Ag system, it is shown here and in [11] that the C/Ti ratio has a strong effect on the Ag grain distribution. The high C/Ti ratio (>1) of Coatings 1-16 (see Table 1) promotes a homogenous distribution of $\mathrm{Ag}$ (c.f. Figure 5). This means that the key to obtain a homogenous distribution of Ag for these growth conditions is the amount of the amorphous matrix, rather than the amount of $\mathrm{SiC}$ [11].

Sn forms an intermetallic phase with Ag and is the only A-element in this study that does not have a eutectic phase diagram with Ag [22]. All Sn-containing coatings contain both $\mathrm{Ag}_{3} \mathrm{Sn}$ and $\mathrm{Ag}$, which is in accordance with the phase diagram [22] for $\mathrm{Sn} / \mathrm{Ag}$ ratios $>0.36$. The peak shift observed in the Ag3d region of the XPS spectra, indicates that $\mathrm{Ag}$ bonds to Sn. In the Sn3d region such shift is not observed, since the difference in electronegativity of $\mathrm{Ag}$ and $\mathrm{Sn}$ is too small. Ag reacts with $\mathrm{Sn}$ with a 3:1 ratio, any remaining $\mathrm{Ag}$ will precipitate. Moreover, the peak shift for $\mathrm{Ag}$ in the $\mathrm{x}$-ray diffractograms indicates incorporation of $\mathrm{Sn}$ in the cubic-Ag phase. According to the phase diagram in [22], up to 9 at.\% Sn can dissolve in Ag. Any excess Sn, as in the Snrich Coatings 15 and 16, will precipitate. These coatings have a homogenous size and distribution of the precipitates, similar to Ti-Si-C-Ag coatings. However, Sn makes the coatings porous, which results in a rough surface morphology, which in turn results in an additional $\mathrm{O}$ uptake. The fact that Coatings 15 and 16 contain more $\mathrm{Sn}, \mathrm{SnO}$, and $\mathrm{TiO}$ than Coatings 13 and 14 indicates that Coatings 15 and 16 are more porous, and that $\mathrm{Sn}$ is 
the major reason for the porosity. This is consistent with sputtered pure Sn coatings [34] that form a porous surface during exposure to oxygen, similar in appearance to Coating 14. Although the contact resistance is lower for the Ti-Sn-C-Ag coatings compared to the Ti-Si-C-Ag coatings, the porosity of these coatings will likely result in poor long-term contact performance.

The presence of $\mathrm{O}$ (see Table 1) in Coatings 1-16 is presumably due to oxidation after the deposition during exposure to the atmosphere. The low $\mathrm{O}$ content in Coatings 1, 2, and 58 is explained by the dense structure, which hinders indiffusion of $\mathrm{O}$. The $\mathrm{N}$ content, on the other hand, is a contamination from the TiC target manufacturing. Similar to graphite targets that have reacted with $\mathrm{N}$ in a sputtering discharge [35], $\mathrm{C}_{\mathrm{x}} \mathrm{N}_{\mathrm{y}}$ molecules can be evaporated or chemically sputtered, and become incorporated in the coating during growth. The $\mathrm{N}$ content, however, has no significant effect on the microstructure or the electrical properties in these Ti-Si-C-Ag coatings. Probably, $\mathrm{N}$ substitutes for $\mathrm{C}$ in the TiC, meaning that a few atomic percent $\mathrm{N}$ in the coating results in a similar microstructure as $\mathrm{Ti}-\mathrm{Si}-\mathrm{C}-\mathrm{Ag}$ coatings without $\mathrm{N}$ [11], which signifies that the process is robust.

From the contact resistance data in Figure $7 \mathrm{a}$ and $\mathrm{c}$, it is apparent from the shape of the curves that the oxides in Coatings 1-4 and 9-12 are relatively easily penetrated. For the latter group, this is likely because Ge induces a thinner and/or less mechanically resilient oxide than the Si and Sn-containing coatings. The shape of the curve for Coatings 1-4 is probably not mainly because of the thin oxide, rather the relatively large Ag particles on the surface. For Coatings 13-16, the contact resistance is higher than for the coatings 
containing Ge, despite the fact that Sn forms conductive oxides. This indicates that the deleterious effect of porosity dominates in these coatings.

\section{Conclusions}

Quaternary-system nanocomposite Ti-A-C-Ag coatings with $(\mathrm{A}=\mathrm{Si}, \mathrm{Ge}, \mathrm{Sn})$ were deposited in an ultra-high vacuum chamber by dc magnetron sputtering. Ti-A-C-Ag coatings obtain improved electrical properties if the formation of the amorphous lowconducting SiC matrix is hindered by substitutions by $\mathrm{Ge}$ and $\mathrm{Sn}$ or by an increased $\mathrm{Ti}$ content. A C/Ti ratio $>1$ gives an amorphous matrix that quenches the segregation of $\mathrm{Ag}$, which results in a homogenous nm-grain size $\mathrm{Ag}$ distribution. The effect of totally removing the $\mathrm{Si}$ in $\mathrm{Ti}-\mathrm{C}-\mathrm{Ag}$ coatings is that of a lower contact resistance. From a chemical point of view, the addition of $\mathrm{Ge}$ and $\mathrm{Sn}$ instead of $\mathrm{Si}$ should increase the conductivity of the coatings due to the formation of more metallic phases, which our results also showed. The resistivity was similar or decreased and the contact resistance was decreased for Ge and Sn coatings compared with Si coatings. The effects of adding $\mathrm{Sn}$ to the Ti-A-C-Ag system is the formation of $\mathrm{Ag}_{3} \mathrm{Sn}$ and $\mathrm{Sn}$ grains. Ti-Ge-C-Ag coatings exhibit Ge precipitation in an amorphous C matrix. Significantly, Ge does not increase the conductance of the $\mathrm{C}$ matrix, but makes the coatings rougher such that the native insulating oxide can be penetrated. Among the coatings studied here, Ti-Ge-C-Ag exhibits the lowest contact resistance and are dense, which makes it the most promising electrical contact material system.

\section{Acknowledgments}


The work was financially supported by the VINNOVA VINN Excellence Centre in Research and Innovation on Functional Nanoscale Materials, FunMat.

[1] M. Antler, Thin Solid Films 84 (1981) 245.

[2] D. Martínez- Martínez, C. López-Cartes, A. Fernández, J. C. Sánchez-López, Thin Solid Films 517 (2009) 1662.

[3] J. Musil, P. Novák, R. Cerstvý, Z. Soukup, J. Vac. Sci. Technol. A 28(2) (2010) 244.

[4] A. A. Voevodin, J. S. Zabinski, J. Mater. Sci. 33 (1998) 319.

[5] T. Zehnder, J. Matthey, P. Schwaller, A. Klein, P.-A. Steinmann, J. Patscheider, Surf. Coat. Technol. 163 (2003) 238.

[6] K. P. Shaha, Y. T. Pei, D. Martinez- Martinez, J. C. Sanchez-Lopez, J. Th. M. De Hosson, Surf. Coat. Technol. 205 (2010) 2633.

[7] P. Vasina, P. Soucek, T. Schmidtová, M. Eliás, V. Bursikoová, M. Jilek, M. Jilek Jr., J. Schäfer, J. Bursik, Surf. Coat. Technol. 205 (2011) S53.

[8] T. Zehnder, P. Schwaller, F. Munnik, S. Mikhailov, J. Patscheider, J. Appl. Phys. 95 (2004) 4327.

[9] O. Wilhelmsson, M. Råsander, M. Carlsson, E. Lewin, B. Sanyal, U. Wiklund, O. Eriksson, U. Jansson, Adv. Funct. Mater. 17 (2007) 1611.

[10] J. Lauridsen, P. Eklund, T. Joelsson, H. Ljungcrantz, Å. Öberg, E. Lewin, U. Jansson, M. Beckers, H. Högberg, L. Hultman, Surf. Coat. Technol. 205 (2010) 299. 
[11] J. Lauridsen, P. Eklund, J. Jensen, H. Ljungcrantz, Å. Öberg, E. Lewin, U. Jansson, A. Flink, H. Högberg, L. Hultman, Acta Materialia 58 (2010) 6592.

[12] P. Eklund, T. Joelsson, H. Ljungcrantz, O. Wilhelmsson, Zs. Czigány, H. Högberg, L. Hultman, Surf. Coat. Technol. 201 (2007) 6465.

[13] E. Lewin, E. Olsson, B. André, T. Joelsson, Å. Öberg, U. Wiklund, H. Ljungcrantz, U. Jansson, Plasma Processes and Polymers 6 (2009) S928.

[14] P. Eklund, J. Emmerlich, H. Högberg, O. Wilhelmsson, P. Isberg, J. Birch, P. O. Å. Persson, U. Jansson, L. Hultman, J. Vac. Sci. Technol. B 23 (2005) 2486.

[15] U. Jansson, E. Lewin, M. Råsander, O. Eriksson, B. André, U. Wiklund, Surf. Coat. Technol. (2010), doi:10.1016/j.surfcoat.2010.06.017.

[16] E. Lewin, O. Wilhelmsson, U. Jansson, J. Appl. Phys. 100 (2006) 054303.

[17] B. André, E. Lewin, U. Jansson, U. Wiklund, Wear 270 (2011) 555.

[18] P. Eklund, Surf. Eng. 23 (2007) 406.

[19] P. Isberg, P. Eklund, J. Emmerlich, L. Hultman, H. Högberg, H. Ljungcrantz, International Patent no. WO2005/038985 A2 (18 October 2004).

[20] M. Rester, J. Neidhardt, P. Eklund, J. Emmerlich, H. Ljungcrantz, L. Hultman, C. Mitterer, Mater. Sci. Eng. A 429 (2006) 90.

[21] W. H. Weber, B.-K. Yang, M. Krishnamurthy, Appl. Phys. Lett. 73 (1998) 626.

[22] T. B. Massalski, Editor. Binary alloy phase diagrams. Metals Park, American Society for Metals, Ohio, 1986.

[23] O. P. Pandey, S. N. Ojha, S. Lele, J. Mater. Sci. Technol., Vol. 13 (1997) 524.

[24] Y. Zhang, H. J. Whitlow, T. Winzell, I. F. Bubb, T. Sajavaara, J. Jokinen, K. Arstila, J. Keinonen, Nucl. Instrum. Methods Phys. Res. B 149 (1999) 477. 
[25] H. Högberg, J. Birch, M. Oden, J-O. Malm, L. Hultman, U. Jansson, J. Mater. Res. 5 (2001) 1301.

[26] HO. Pierson, Handbook of refractory carbides and nitrides, Noyes Publication, London, 1996.

[27] E. Lewin, P. O. Å. Persson, M. Lattemann, M. Stüber, M. Gorgoi, A. Sandell, C. Ziebert, F. Schäfers, W. Braun, J. Halbritter, S. Ulrich, W. Eberhardt, L. Hultman, H. Siegbahn, S. Svensson, U. Jansson, Surf. Coat. Technol. 202 (2008) 3563.

[28] M. Magnuson, E. Lewin, L. Hultman, U. Jansson, Phys. Rev. B 80 (2009) 235108.

[29] E. Lewin, M. Gorgoi, F. Schäfers, S. Svensson, U. Jansson, Surf. Coat. Technol. 204 (2009) 455.

[30] B. V. Crist, Monochromatic XPS spectra - The elements and native oxides, Wiley, Chichester, 2000.

[31] R. Holm, Electric contacts - Theory and applications, Reprint of the forth completely rewritten edition, $1967,3^{\text {rd }}$ printing, Springer, Berlin, 2000

[32] P. Eklund, C. Virojanadara, J. Emmerlich, L. I. Johansson, H. Högberg, L. Hultman, Phys. Rev. B 74 (2006) 045417.

[33] J. M. Poate, K. N. Tu, J. W. Mayer (Eds.), Thin Films-Interdiffusion and reactions, Wiley, New York, 1978, pp. 359-406

[34] N. Barsan, M. Schweizer-Berberich, W. Göpel, J. Anal. Chem. 365 (1999) 287

[35] J. Neidhardt, L. Hultman, J. Vac. Sci. Technol. A 25(4) (2007) 633. 
Table 1. Resistivity and composition (unit is at.\%) of Coatings 1-16

$\begin{array}{cccccccc}\text { Coating } & \mathbf{T i} & \mathbf{A} & \mathbf{C} & \mathbf{A g} & \mathbf{O} & \mathbf{N} & \begin{array}{c}\text { Resistivity } \\ (\boldsymbol{\mu} \boldsymbol{\mathbf { c m }})\end{array} \\ 1 & 29.1 & & 58.7 & 6.1 & 0.2 & 5.9 & 279 \\ 2 & 29.3 & & 51.6 & 13.8 & 0.7 & 4.6 & 239 \\ 3 & 34.9 & & 51 & 4.7 & 4.8 & 4.6 & 401 \\ 4 & 36.3 & & 42.9 & 13.3 & 3.5 & 4 & 200 \\ & & \mathbf{S i} & & & & & \\ 5 & 24.2 & 9.4 & 55.5 & 3.8 & 0.7 & 6.4 & 520 \\ 6 & 22.5 & 9.1 & 50.2 & 11.9 & 0.7 & 5.6 & 378 \\ 7 & 19.8 & 20.5 & 49.9 & 4.7 & 0.2 & 4.9 & 1094 \\ 8 & 17.7 & 20.9 & 45.8 & 11.5 & 0.1 & 4 & 483 \\ & & \mathbf{G e} & & & & & 470 \\ 9 & 25.5 & 9.5 & 49.7 & 8.5 & 2.1 & 4.6 & 274 \\ 10 & 21.6 & 8.2 & 43.4 & 17.2 & 5.2 & 4.3 & 1013 \\ 11 & 20.2 & 25 & 40.1 & 7.3 & 3.6 & 3.7 & 578 \\ 12 & 19.1 & 22.7 & 36.4 & 14.4 & 4 & 3.3 & \\ & & \mathbf{S n} & & & & & \\ 13 & 29.9 & 3.5 & 53.8 & 2.9 & 4.3 & 5.6 & 463 \\ 14 & 27.5 & 2.9 & 52.5 & 7.6 & 4.7 & 4.9 & 491 \\ 15 & 24.2 & 15.2 & 43.7 & 4 & 8.4 & 4.6 & 735 \\ & 23.5 & 15.1 & 44.2 & 7.4 & 8.1 & 1.8 & 715\end{array}$

